L'Argus. Premier journal du département de la Manche (Coutances, juin-juillet 1790) précédé d'une notice sur son rédacteur Pierre-CharlesFrançois Mithois (1760-v. 1800)

\title{
Raymonde Monnier
}

\section{(2) OpenEdition \\ Journals}

\section{Édition électronique}

URL : https://journals.openedition.org/ahrf/1114

DOI : 10.4000/ahrf.1114

ISSN : $1952-403 X$

\section{Éditeur :}

Armand Colin, Société des études robespierristes

\section{Édition imprimée}

Date de publication : 1 juin 2001

Pagination : 205

ISSN : 0003-4436

\section{Référence électronique}

Raymonde Monnier, «L'Argus. Premier journal du département de la Manche (Coutances, juin-juillet 1790) précédé d'une notice sur son rédacteur Pierre-Charles-François Mithois (1760-v. 1800) », Annales historiques de la Révolution française [En ligne], 324 | avril-juin 2001, mis en ligne le 10 avril 2006, consulté le 24 avril 2022. URL : http://journals.openedition.org/ahrf/1114 ; DOI : https://doi.org/ 10.4000/ahrf.1114

Ce document a été généré automatiquement le 24 avril 2022.

Tous droits réservés 
L'Argus. Premier journal du département de la Manche (Coutances, juin-juillet 1790)
précédé d'une notice sur son rédacteur Pierre-Charles-François Mithois (1760-v. 1800)

\author{
Raymonde Monnier
}

\title{
RÉFÉRENCE
}

Dr Hugues Plaideux, L'Argus. Premier journal du département de la Manche (Coutances, juinjuillet 1790) précédé d'une notice sur son rédacteur Pierre-Charles-François Mithois (1760-v. 1800), Revue de la Manche, t. 42, 2000, fasc. 166-167, 153 p., 120 F (Société d'archéologie et d'histoire de la Manche, Archives départementales, BP 540, 50010 Saint-Lô cedex).

1 Ce numéro spécial de la Revue de la Manche est consacré à la présentation et à la réédition des neuf numéros d'un journal de province, l'Argus ou l'homme aux cent yeux, Journal du département de la Manche et de tous les départements françois, par une Société de littérateurs patriotes. Son directeur, Mithois, était déjà connu comme militant de la section de l'unité à Paris, notamment pour avoir fait partie du comité central révolutionnaire du 31 mai. Commissaire du Conseil exécutif, puis employé à la commission d'Instruction publique en l'an II, Mithois est un agent jacobin dont l'activité patriotique entre Paris et Coutances méritait d'être approfondie. L'auteur retrace autant que faire se peut son rôle dans les sociétés populaires locales, en étroite liaison avec son activité de journaliste. Mithois est un de ces militants révolutionnaires que la liberté de la presse engage comme beaucoup d'autres à user de ses talents 
littéraires pour éclairer ses concitoyens, et les inviter à former, comme il l'écrit dans le prospectus de l'Argus, «une ligue heureuse d'opinions, de sentiments et de vues» contre l'aristocratie et l'ignorance. Il se signalera encore à Paris après Thermidor, comme directeur, rédacteur et imprimeur du Télégraphe politique, organe de la Société des hommes révolutionnaires du 10 Août, ce qui lui vaudra d'être recherché en prairial an III.

La brève carrière de l'Argus - juin-juillet 1790 - correspond, et ce n'est sans doute pas un hasard, avec la tenue de l'Assemblée électorale du département de la Manche, qui tient ses séances à Coutances du 14 au 23 juin 1790. Les "Littérateurs patriotes» qui sont à l'origine du journal sont vraisemblablement les membres les plus actifs de la Société patriotique et littéraire fondée quelques mois plus tôt; une députation de la société vient le 17 juin inviter les membres de l'assemblée électorale à «honorer de leur présence ce Club citoyen», demandant en échange que ses membres soient autorisés à assister à leurs opérations. Le premier numéro de l'Argus, daté du 15 juin, relate la cérémonie d'ouverture de l'Assemblée des électeurs; l'événement est d'importance et les numéros suivants sont presque entièrement consacrés aux comptes rendus de ses séances. La publication de l'Argus témoigne de la mobilisation des patriotes pour ces premières élections qui sont perçues comme un enjeu important. Une fois élus les administrateurs du département, les derniers numéros rendent compte des élections municipales et de la préparation de la fédération, mais le journal se fait aussi l'écho de dissensions dans la garde nationale, en liaison avec un conflit local dont le Dr Plaideux retrace les principales lignes en introduction. Son étude très érudite éclaire divers aspects de la politique à Coutances sous la Révolution; elle est complétée de plusieurs index (noms de personnes, auteurs, lieux, matières), y compris pour le texte du journal, et d'une table de l'Argus, ce qui en facilite grandement l'exploitation. Cette publication n'intéressera pas seulement les historiens locaux, elle sera utile à tous ceux qui s'intéressent à la politique et aux élections révolutionnaires. 